\title{
Complex electronic protection for low-voltage three-phase induction motors
}

\author{
GABRIEL NICOLAE POPA ${ }^{1, *}$, CORINA MARIA DINIȘ ${ }^{1}$ \\ ${ }^{1}$ Politehnica University Timișoara, Department of Electrical Engineering \\ and Industrial Informatics, 331128 Revolutiei Str., \\ No.5 Hunedoara, ROMANIA
}

\begin{abstract}
Low-voltage three-phase induction motors are most often used in industrial electric drives. Electric motors must be protected by electric and/or electronic devices against: short-circuit, overloads, asymmetrical currents, two-phase voltage operation, under-voltage, and over-temperature. To design the electronic protection currents, voltages and temperature must be measured to determine whether they fall within normal limits. The electronic protection was design into low capacity PLC. The paper presents the designs and analysis of complex electronic protection for general purpose low-voltage three-phase induction motors. The electronic protection has Hall transducers and conversion electronic devices for AC currents to DC voltages, $\mathrm{AC}$ voltages to $\mathrm{DC}$ voltage, temperature to DC voltage, a low capacity PLC, switches, motor's power contactors, and signalling lamps has been developed. Experiments with complex electronic protection, for different faults are presented. The proposed protection has the advantages of incorporating all usual protections future for the low-voltage three-phase induction motors.
\end{abstract}

Keywords: Electronics, Electronic Protection, Induction Motors, electronic protection current

Received: May 4, 2019. Revised: December 12, 2019. Accepted: December 29, 2019.Published: January 14, 2020.

\section{Introduction}

Most electrical industrial loads are low-voltage threephase squirrel cage induction motors. The advantages of using these electrical motors are simple construction, rugged, reliable, and, also, economical [1-3].

In industry, the main types of faults of low-voltage three-phase squirrel cage induction motors are: short circuits between stator winding coils, interruption of a coil, the grounding of stator coil conductors, and electric insulation failure. There are, also, complex faults that are combinations of main types of simple faults. Less used in industry are three-phase wound rotor induction electric motors. For these electric motors, faults occurring in the stator and, also, in the rotor winding [49]. There are a lot of electric and electronic protective devices for low-voltage three-phase induction motors. They must operate to interrupt power supply (immediately or timed) with electrical power (via the contactors) in the event of a faults in the power electrical installation or inside the electrical motor [10-12].

The squirrel cage induction motors are very widely used in both fixed speed and variable frequency drive applications. In the present days, with the development of the power electronics, there are applications with static frequency converters (SFCs) which supplies and controls three-phase induction motors. SFCs are performing and have all protections for three-phase induction motors. There are still many applications that do not use SFCs, and induction motors must to be protected with classical protection (electric and/or electronic protective devices) $[2,3,5,13]$.

\section{Protections for low-voltage three-phase induction motors}

In domestic or industrial applications, low-voltage threephase induction motors are provided with the following types of protections, in the one or many solid state devices, against $[4-7,10,11]$ :

- the short-circuits inside the electric motor;

- the mechanical or electrical overloads;

- the asymmetrical of motor currents;

- the two-phase voltage motor operation;

- the supply under-voltage;

- the over-temperature in the motor stator;

- the combined protection against two or more types of faults.

Usually, the protections of the induction motors can be made with electrical and/or electronic devices, and measure the currents (I) and/or voltages (U), and/or temperatures $(t)$, and compare them with the nominal values (In, Un, tn). Complex protections can provide many types of protections for low-voltage three-phase induction motors. For classical applications, the 
protections act instantaneously or timed-on the power contactors that supply the motor [5].

A short-circuit in the motor stator can create dangerous high value of currents (usually, over $7 \cdot \operatorname{In}$ ) and the motor must be turned-off immediately. Overload protection is used to protect the motor from high mechanical load, short circuit between coil or layers windings (due the aging insulation). Phase current may have values greater than the nominal value, but less than the short-circuit current. The protection works timed, with less and less time, for the higher values of the current [6]. If the current on a phase differs (e.g. by about 30\%) from the currents on the other phases, the asymmetrical protection timed can act, and the motors turned off [10].

A common cause of failure of three-phase induction motors is the two-phase operation as a result of the burning of a fuse from the power supply, the interruption of a conductor in the electrical installation or from motor windings. The current on the other two phases increase (e.g. by approx. 50\%), and the motor must be immediately stopped by the protection against two-phase operation [14]. Sometimes, the motor's supply voltage (e.g. due the network loading) drops below acceptable limits (under $70 \%$ of the nominal voltage), which results in a strong torque drop. Timed, the under-voltage protection must turn off the motor.

If the motor is operated with high mechanically load, the motor will warm up over the acceptable insulation limits, leading to premature deterioration. The thermal protections can be used, which are based on the thermistor mounted in the stator, which can timed stopped the motor $[7,15]$.

\section{Measuring currents, voltages and temperature at low-voltage three-phase induction motors}

Complex protection for three-phase induction motors is presented. The protection can be used for low-voltage three-phase squirrel-cage induction motors in star or delta connection, without or with null. For electronic protection device is measured the phase currents, line voltages and the temperature in the motor stator. The protection is made with Zelio PLC, which has digital, analogue inputs, and digital outputs [16].

Three current devices were used to measure phase currents (on L1, L2, and L3) with current Hall transducers type LA 55-P/SP1 (LEM), which can measure RMS nominal currents up to $50 \mathrm{~A}$ and the output current of $25 \mathrm{~mA}$ (Fig.1). At the output of Hall transducer a resistance $\left(\mathrm{R}_{\mathrm{M}}\right)$ was used in the measuring (secondary) circuit of LEM's. For the RMS current at the input of Hall transducer, the voltage drop on the measuring resistance $R_{M}$ is obtained an $A C$ voltage that is proportional with AC current. The AC voltage can't be used directly at the input of the PLC (that accepts only $\mathrm{DC}$ voltages). The AC voltage on resistor $\mathrm{RM}$ is rectified with the precision full wave rectifier (IC1 and auxiliary components), a low-pass active filter (IC2 and auxiliary components), and a non-inverting amplifier with operational amplifier (IC3 and auxiliary components). At the output of IC3, a DC voltage is obtained that is proportional with AC phase current of the motor (Fig.2).

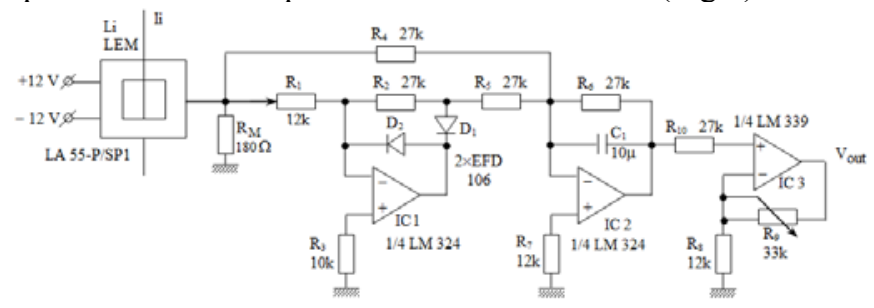

Fig. 1. Electronic device that convert AC current to DC voltage.

For the electronic device from Fig.1, at the input of current Hall transducer, an AC current (RMS) was connected at the input (input of Hall transducer) and was measured the voltage at the output (IC3, DC voltage). The dependence between output DC voltage and input $\mathrm{AC}$ current is almost linear. The maximum output value for PLC analogue input is $10 \mathrm{~V}$ that correspond for $20 \mathrm{~A}$ (e.g. for induction motor with $11 \mathrm{~kW}, 1475 \mathrm{rpm}$ ).

The DC output voltage of the electronic device from Fig.1 is presented in Fig.3 for two input AC current (at Hall transducer). The output voltage is continuous and is proportional with the input AC current [10].

To measuring AC currents of the motor are used three electronic devices (Fig.1) and three PLC analogue inputs $(0-10 \mathrm{~V})$. The electronic device from Fig.1 is used to short-circuit, asymmetrical, and overload protections of the three-phase induction motor.

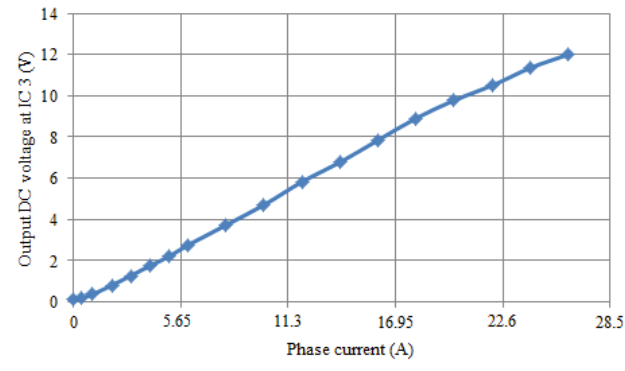

Fig. 2. The ouput DC voltage depending on AC phase current for electronic device from Fig.1.

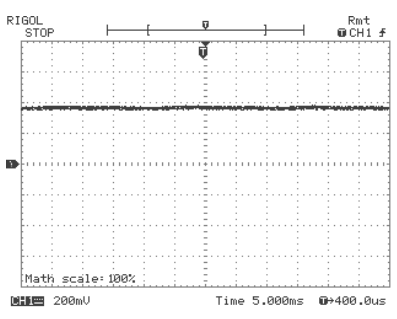

a.

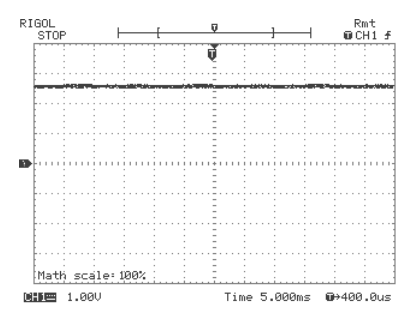

b.
Fig. 3. DC voltages at the output of IC3 (the output of circuit from Fig.1) for input AC current: a. 2.1 A; b. 14.6 A.

Two voltage devices were used to measure line voltages (L1-2, L2-3) with voltage Hall transducers type LV 25-800 (LEM), which can measure RMS nominal voltages up to $800 \mathrm{~V}$ and the output current of $25 \mathrm{~mA}$ (Fig.4). At the output of Hall transducer a resistance $\left(R_{M}\right)$ was used in the measuring (secondary) circuit of LEM's. For the RMS voltage at the input of Hall device, 
the voltage drop on the measuring resistance $R_{M}$ is obtained an $\mathrm{AC}$ voltage that is proportional with $\mathrm{AC}$ voltage. The AC voltage can't be used directly at the input of the PLC. The AC voltage on resistor $R_{M}$ is converted into DC voltage using the same circuits like in Fig.1. At the output of IC3, a DC voltage is obtained that is proportional with line voltage of the motor (Fig.5).

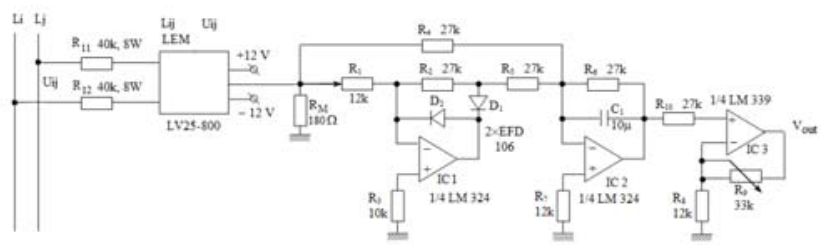

Fig. 4. Electronic device that convert $\mathrm{AC}$ voltage to $\mathrm{DC}$ voltage.

For the electronic device from Fig.4, at the input of voltage Hall transducer, an AC voltage (RMS) was connected at the input (input of Hall transducer) and was measured the DC voltage at the IC3 output.

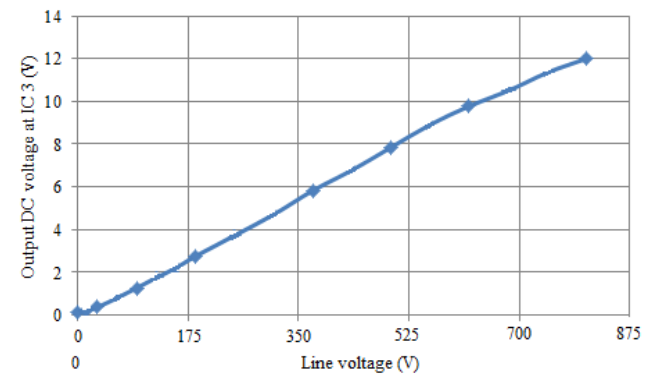

Fig. 5. The ouput DC voltage depending on AC line voltage for electronic device from Fig.4.

The dependence between output DC voltage and input $\mathrm{AC}$ voltage is almost linear. The maximum output value for PLC analogue input is $10 \mathrm{~V}$ that is line voltage $612 \mathrm{~V}$.

To measure AC line voltages of the motor are used two electronic devices (Fig.4) and two PLC analogue inputs $(0-10 \mathrm{~V})$. The electronic device from Fig.4 is used to under-voltage and two-phase operation of the induction motor.

To measure the temperature in motor stator is used the electronic device from Fig.6 that used a NTC thermistor $\left(2.7 \mathrm{k} \Omega\right.$ at $\left.25^{\circ} \mathrm{C}\right)$ in a bridge connection using a comparator (IC). At the output is a DC voltage that depend on the temperature of the stator.

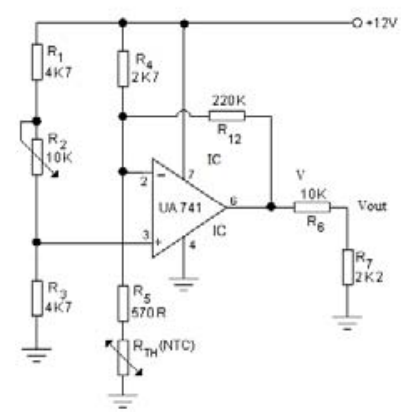

Fig. 6. The electronic device to temperature measure.
In Fig.6, for $R_{2}=5 \mathrm{k} \Omega$ when $\mathrm{R}_{\mathrm{t}}=0.213 \mathrm{k} \Omega\left(\mathrm{t}=95^{0} \mathrm{C}\right)$, $\mathrm{V}_{2}=2.25 \mathrm{~V}, \mathrm{~V}_{6}=1.81 \mathrm{~V}$ and $\mathrm{V}_{\text {out }}=1.01 \mathrm{~V}$.

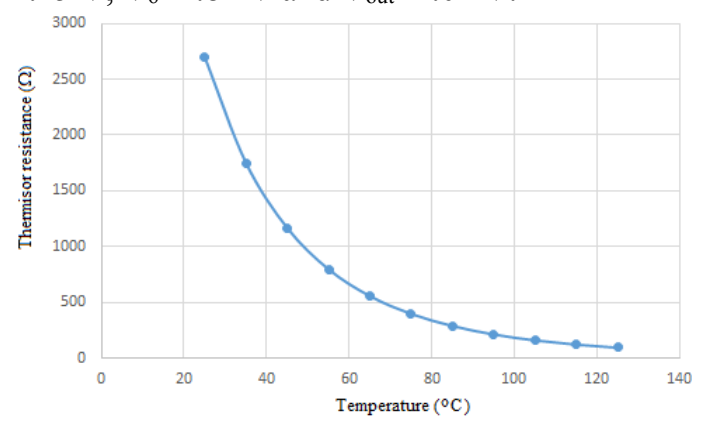

Fig. 7. The NTC thermistor characteristics used in Fig.6.

For temperature measurements is used only one electronic device (Fig.6) with NTC thermistor and one PLC analogue input $(0-10 \mathrm{~V})$. The electronic device from Fig. 6 is used to over-temperature of the three-phase induction motor.

For measurements from Figs. 2,5,7, Protek 506 TRMS multimeters were used.

\section{Complex electronic protection with PLC for induction motors}

The PLC which has been tested and implemented complex protection for inductions motors is Zelio SR3 B261BD (Fig.8, Schneider) powered by 24V DC with 16 inputs (ten digital I1 to IA, and six analogue IB, IC, ID, IE, IF, and IG), and eight outputs (Q1 to Q8) relay contact types. It can be programmed in LD (ladder diagram) or FBD (function block diagram) [16]. For programming was used FBD.

The protection has been applied to a classic application, which is common in practice, of low-voltage three-phase squirrel cage induction motors, with one stop switch and two start switches, that works forward and backward. Changing the direction of rotation is achieved by inverting two phases of the supply voltage (with contactor $\mathrm{K}_{2}-$ Fig. 8 ).

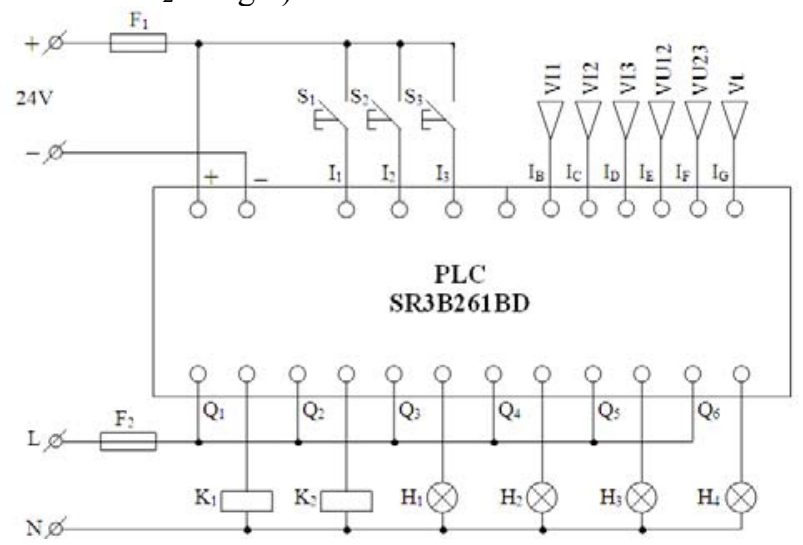

Fig. 8. Zelio PLC type SR3 B261BD powered at 24 V DC.

For PLC, the six analogue inputs support DC voltage, between 0 and $10 \mathrm{~V}$ ( 0 to 255 decimal in FBD), and the conversion is on 8 bits [16,17].

When performing the complex protection, the phase currents of the motor are measured with electronic 
devices from Fig.1 on IB (VI1), IC (VI2), and ID (VI3) analogue inputs, the line voltages with electronic devices from Fig.4 on IE (VU12) and IF (VU23) analogue inputs, and the temperature is measurement with electronic device from Fig.6 on IG (Vt) analogue input. From the ten digital inputs there are used only three: I1(S1) that is Stop switch, I2(S2) that is forward rotation of the motor, and I3(S3) that is backward rotation of the motor.

In application is used six digital outputs: Q1 (contactor K1) for forward rotation of the motor, Q2 (contactor K2) for backward rotation of the motor, Q3 (lamp H1) for Stop (motor off-state), Q4 (lamp H2) for protection operation (motor off-state), Q5 (lamp H3) for forward rotation of the motor (motor on-state), and Q6 (lamp H4) for backward rotation of the motor (motor onstate). The FBD program implemented in the PLC permanently measures phase currents on each phase (I1, $\mathrm{I} 2, \mathrm{I} 3)$, line-voltage (U12, U23) and temperature in the motor's stator $(\mathrm{t})$. The flowcharts of the program are shown in Figs. 9 and 10.

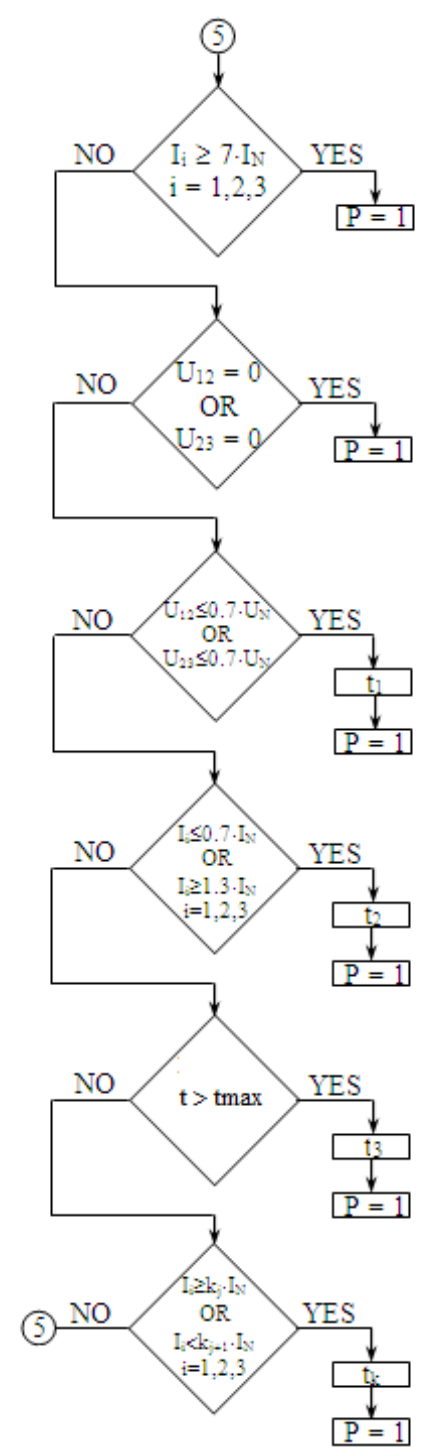

Fig. 9. The flowchart for measuring phase currents, line voltages and the temperature for protection operation.
Fig. 9 shows a flowchart for the protection operation ( $\mathrm{P}=1$, the protection is on and the motor is stopped). For short circuit protection, if any of the phase currents I1, $\mathrm{I} 2$, or $\mathrm{I} 3$ are greater than $7 \cdot \mathrm{In}$, the protection is on $(\mathrm{P}=1)$, instantaneously, and the motor is stopped. For protection for two-phase operation, if any of the two line voltages are $\mathrm{U} 12$ or $\mathrm{U} 23$ is 0 , the protection is on $(\mathrm{P}=1)$, instantaneously, and the motor is stopped. If any of the line voltages are $\mathrm{U} 12$ or $\mathrm{U} 23$ are $\leq 0.7 \cdot \mathrm{Un}$, the protection is under-voltage and a delay $\mathrm{t}_{1}(10 \mathrm{~s})$ is triggered, which after the timing passes will cause protection is on $(\mathrm{P}=$ 1 ), and the motor is stopped. For protection against asymmetrical, if one of the phase currents I1, I2, or I3 is $0.7 \cdot \operatorname{In} \leq \operatorname{In} \leq 1.3 \cdot \operatorname{In}, i=1,2,3$ then a delay $t_{2}(30 \mathrm{~s})$ is triggered, which after the timing determine the protection is on $(\mathrm{P}=1)$, timed and the motor is stopped.

If any of the phase currents is $1.05 \cdot \operatorname{In} \leq \mathrm{Ii}<7 \cdot \operatorname{In}, \mathrm{i}=$ $1,2,3$, then the overload protection with the variable time tk (Table 1) that depends on the current value is triggered. After the timing passes, it will cause protection on $(\mathrm{P}=1)$, and timed the motor is stopped. In Table 1, Udec(-) is the decimal value of overload currents $(\mathrm{k} \cdot \mathrm{In})$ inside PLC.

Table 1. Dependence between the overload currents and time $[2,5,7]$.

\begin{tabular}{|c|c|c|}
\hline $\mathbf{k ~ ( - )}$ & Udec (-) & tk (s) \\
\hline 1.05 & 31 & 1800 \\
\hline 1.08 & 32 & 600 \\
\hline 1.1 & 33 & 300 \\
\hline 1.3 & 39 & 40 \\
\hline 1.5 & 45 & 20 \\
\hline 1.8 & 54 & 10 \\
\hline 2.1 & 63 & 2 \\
\hline 3 & 90 & 1 \\
\hline 4 & 120 & 0.2 \\
\hline 5 & 150 & 0.1 \\
\hline 6 & 180 & 0.05 \\
\hline
\end{tabular}

The two-phase operation of the motor is done by the flowchart from Fig.10. The symbols used in Fig. 10 have the meaning of Fig. 8. Check the state of the stop switch $\mathrm{S} 1$, the forward start switch S2, and the backward start switch S3, and the applied protection will permanently check the phase currents, line voltages and the temperature inside the stator to meet the limit values. If these values exceed the set values, the protection is triggered instantaneously or timed, depending on the type of fault.

The FBD program implemented in the PLC is shown in Fig. 11. 


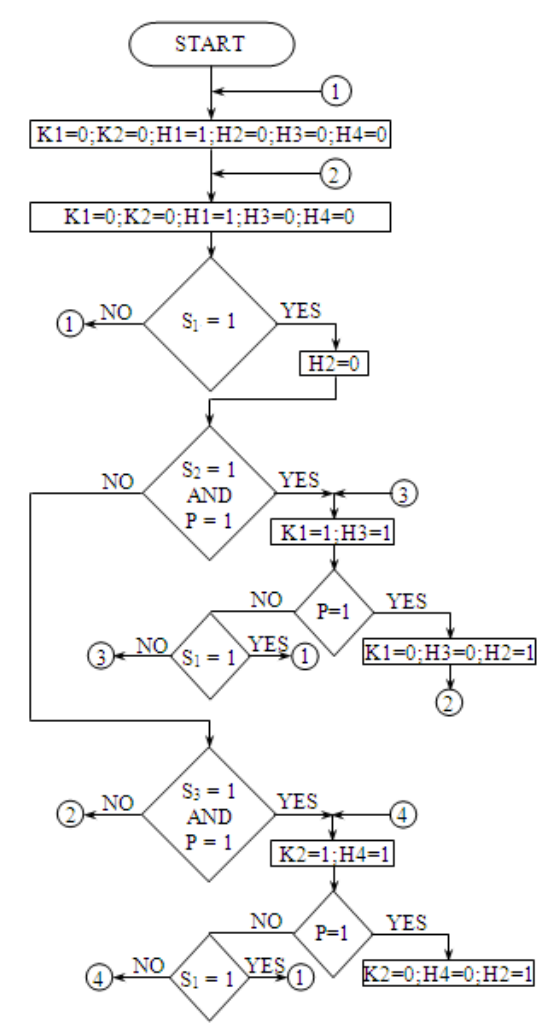

Fig. 10. The flowchart for induction motor control, protection, and signalling.

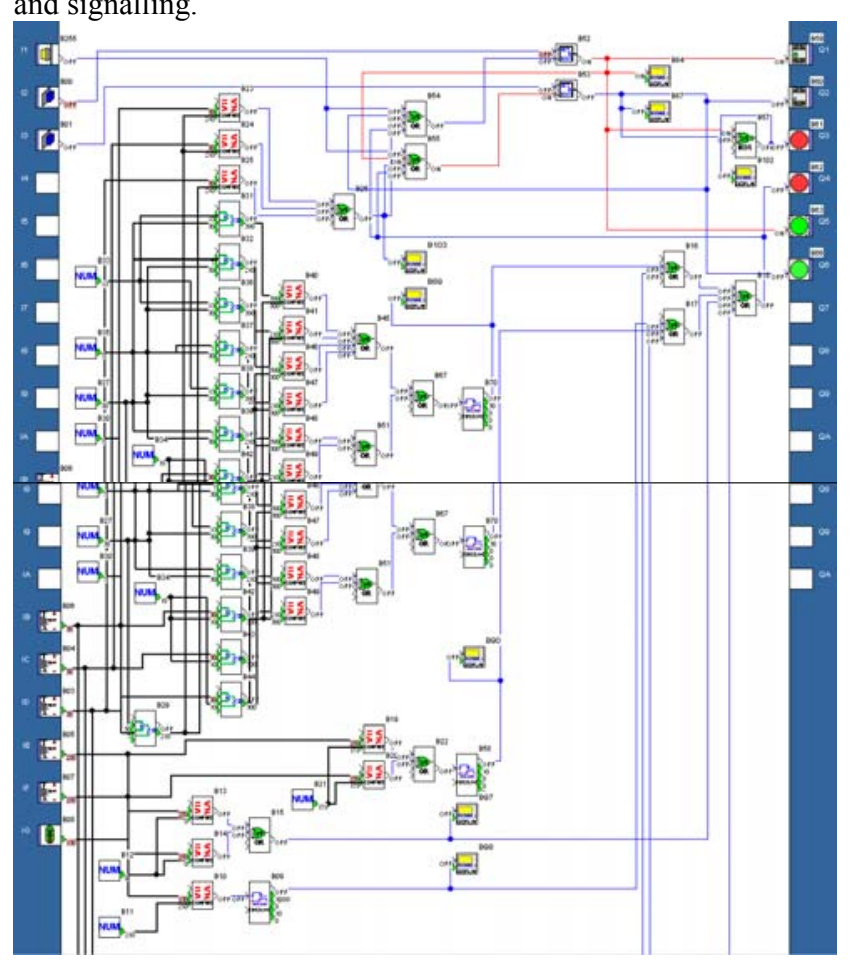

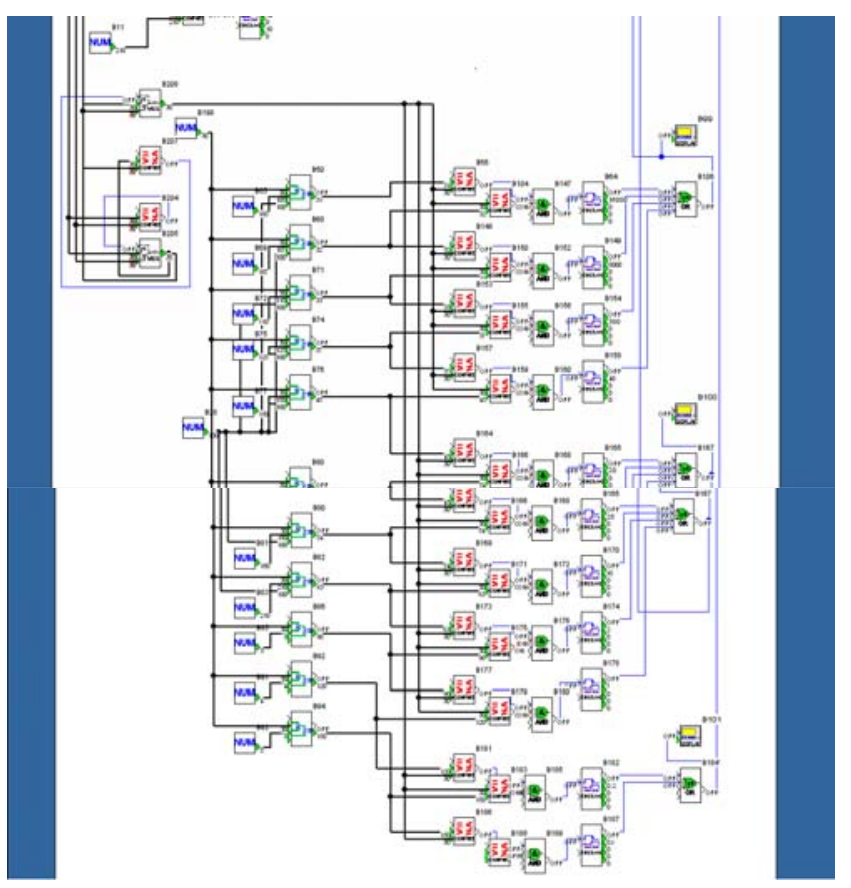

Fig. 11. The FBD program for induction motor control, protection, and signalling.

\section{Complex electronic protection experimentation}

For experimentation a squirrel cage three phase induction motor with the power $1.1 \mathrm{~kW}, 930 \mathrm{rpm}, 2.84 \mathrm{~A}$ (2.84 A is 30 decimal value inside the PLC) is used $[14,15]$. The switches used at the PLC input are without mechanical locking. If the motor is stopped or if $\mathrm{I} 1=1$ ( $\mathrm{S} 1$ is switch on, stop switch), Q1 $=\mathrm{Q} 2=0$ (K1, K2 contactors are turn-off) and $\mathrm{Q} 3=1(\mathrm{H} 1=1$, motor stopped lamp), $\mathrm{Q} 4=0(\mathrm{P}=0$, protection doesn't work $), \mathrm{Q} 5=\mathrm{Q} 6=0$ $(\mathrm{H} 3=\mathrm{H} 4=0)-$ Fig. 11.

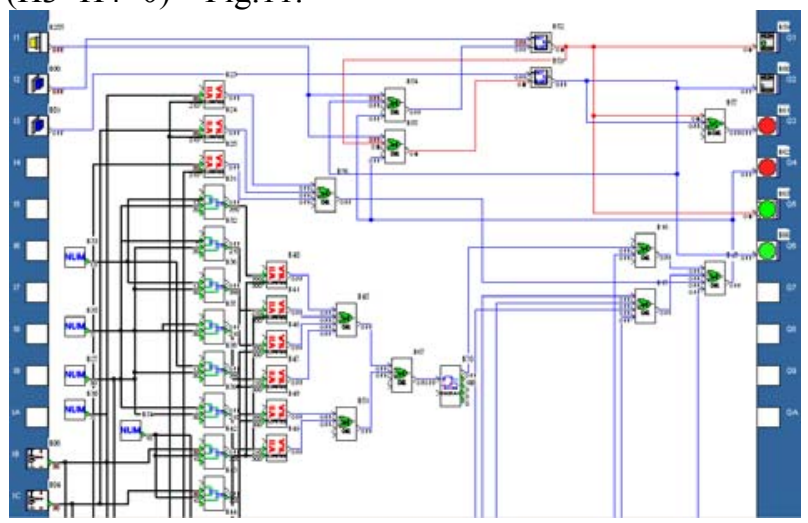

Fig. 12. The FBD program during forward starting of the induction motor. 


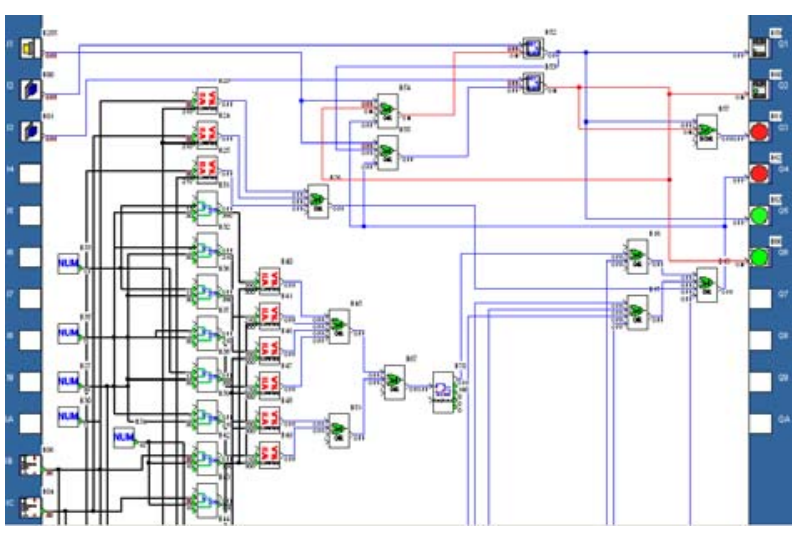

Fig. 13. The FBD program during backward starting of the induction motor.

If the protection doesn't work $(\mathrm{P}=0)$, when $\mathrm{I} 2=1$ ( $\mathrm{S} 2$ is switch on, forward switch), Q1 $=1(\mathrm{~K} 1=1$, forward start contactor), the motor starts in forward, $\mathrm{Q} 2=0(\mathrm{~K} 2=0)$, $\mathrm{Q} 3=\mathrm{Q} 4=0(\mathrm{H} 1=\mathrm{H} 2=0), \mathrm{Q} 6=0(\mathrm{H} 4=0)$, and $\mathrm{Q} 5=1(\mathrm{H} 3=$ 1, forward motor lamp) - Fig. 12 .

If the protection doesn't work $(\mathrm{P}=0)$, when $\mathrm{I} 3=1$ ( $\mathrm{S} 3$ is switch on, backward switch), Q2=1 (K2=1, backward start contactor), the motor starts in backward, $\mathrm{Q} 1=0$ $(\mathrm{K} 1=0), \mathrm{Q} 3=\mathrm{Q} 4=0(\mathrm{H} 1=\mathrm{H} 2=0), \mathrm{Q} 5=0(\mathrm{H} 3=0)$, and $\mathrm{Q} 6=$ 1 ( $\mathrm{H} 4=1$, backward motor lamp)- Fig. 13.

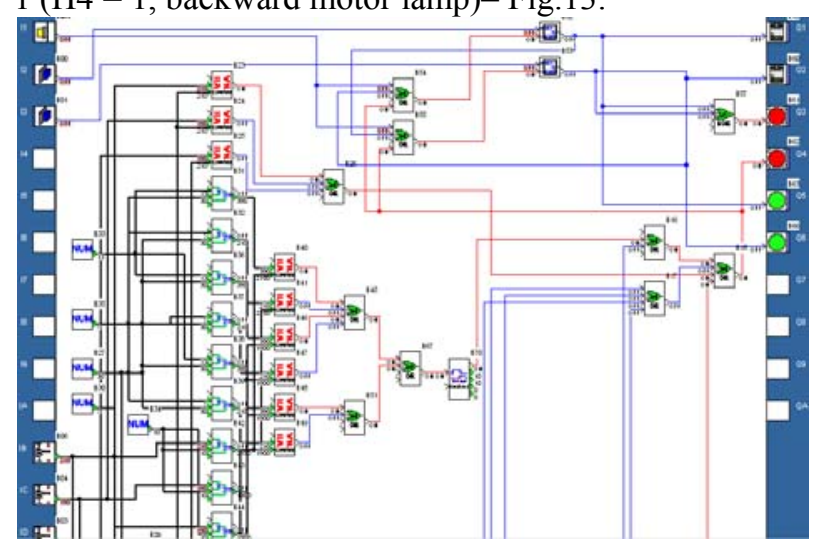

Fig. 14. The FBD program during short circuit protection of the induction motor.

If a short-circuit occurs ( $\mathrm{I} \geq 7 \cdot \mathrm{In}, 210$ decimal) inside the motor, the short-circuit protection is switched-on, and the motor stopped immediately. The switching time is $25-30 \mathrm{~ms}$ and depends the program cycling and the response time of the contactor (Fig.14). The motor must be protected with fuses on each phase.

At every faults detected by the protection: $\mathrm{Q} 1=\mathrm{Q} 2=0$ (K1, K2 is switched off), Q3=1 (H1=1 motor stopped lamp), $\mathrm{Q} 4=1$ ( $\mathrm{P}=1$, protection lamp), and $\mathrm{Q} 5=\mathrm{Q} 6=0$ $(\mathrm{H} 3=\mathrm{H} 4=0)$.

If the line voltage is under $\leq 0.7 \cdot \mathrm{Un}(280 \mathrm{~V}, 105$ decimal), after the time $\mathrm{t} 1(10 \mathrm{~s})$, the motor is turned-off (Fig.15). If one of the line voltage is 0 , the motor is stopped immediately (protection against two-phase voltage operation).

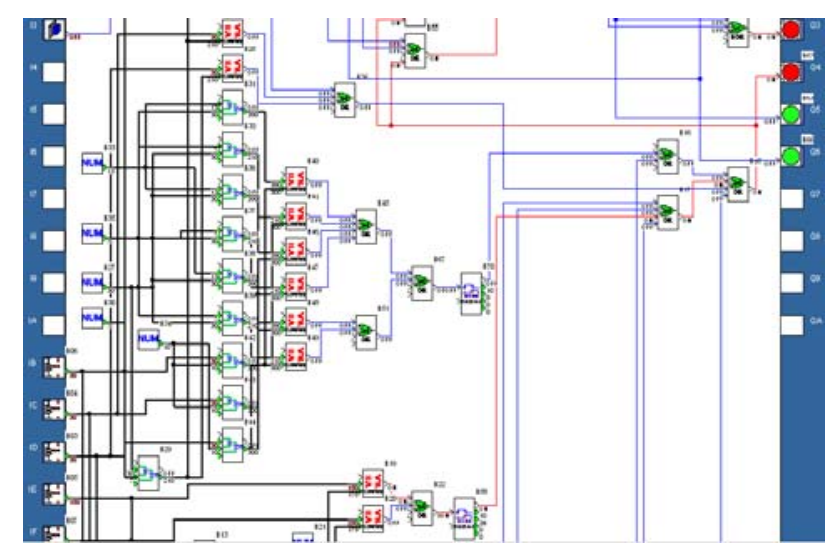

Fig. 15. The FBD program during under voltage protection of the induction motor.

During normal motor operation, one phase current it is different than nominal value $(0.7 \cdot \operatorname{In} \leq \operatorname{In} \leq 1.3 \cdot \operatorname{In}, 21$ to 39 decimal), the asymmetrical protection work and after the time t2 (30 s), the motor is turned-off (Fig.16).

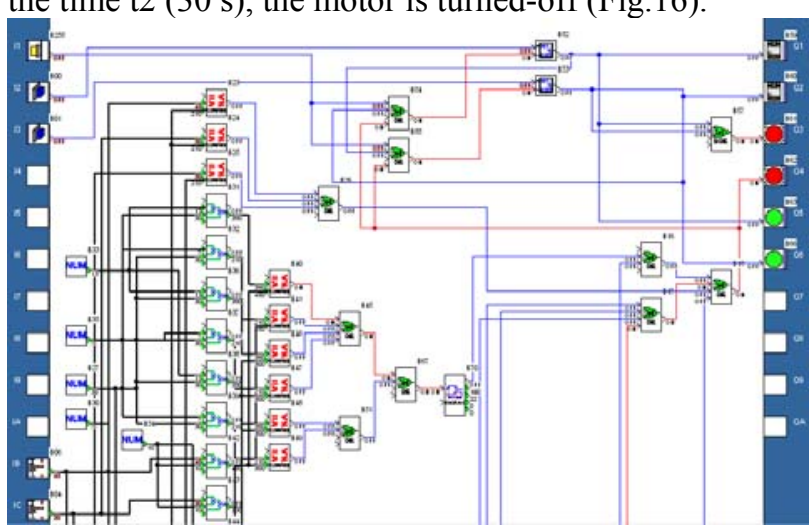

Fig. 16. The FBD program during asymmetrical currents protection of the induction motor.

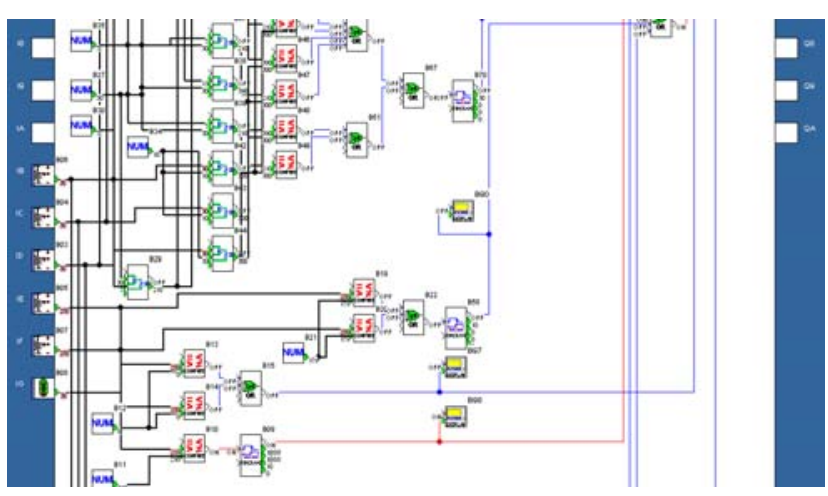

Fig. 17. The FBD program during over-temperature protection of the induction motor.

If the temperature inside the motor exceed the maximum temperature $\left(\mathrm{t}_{\max }=95{ }^{\circ} \mathrm{C}, 26\right.$ decimal $)$, after the time $t_{3}(30 \mathrm{~min}$.), the motor is turned-off (Fig.17). The heating of the motor during experimentation is presented in Fig. 18.

If one phase-current is $1.05 \cdot \operatorname{In} \leq \mathrm{I}<7 \cdot \mathrm{In}$ ( $3 \mathrm{~A}$ to $19.88 \mathrm{~A}$, 31 to 210 decimal), then the overload protection is detected and the variable time tk (Table 1) that depends on the current value is triggered. After the timing passes, the motor is stopped (Fig.19). 


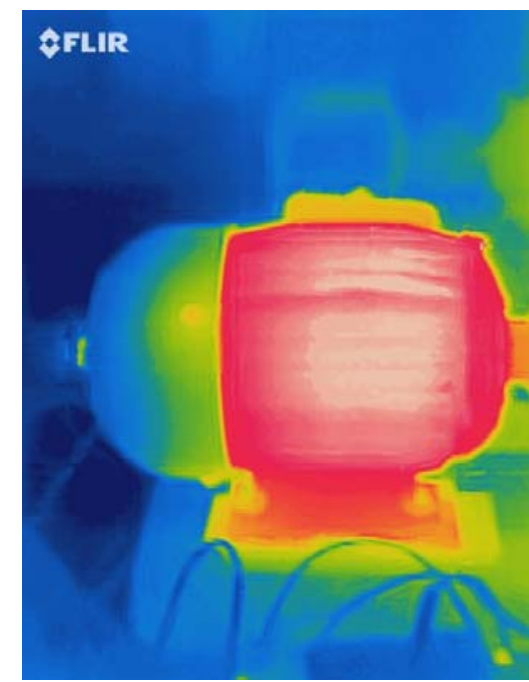

Fig. 18. The heating of the motor during experimentation.
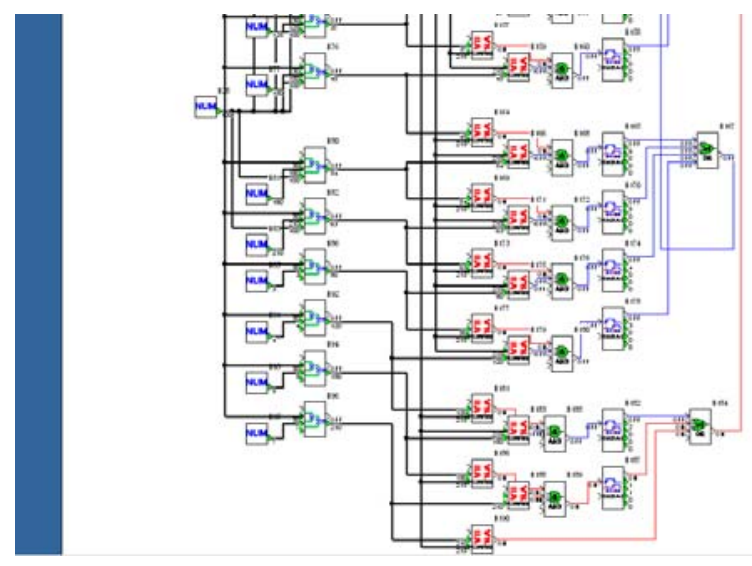

Fig. 19. The FBD program during overload protection of the induction motor.

\section{Conclusions}

PLCs have multiple industrial applications. It has been shown a complex electronic protection (short-circuit, two-phase operation, under-voltage, asymmetrical currents, over-temperature and overload) for the lowvoltage three-phase squirrel cage induction motors. The main components from electronic protection are: electronic devices that convert $\mathrm{AC}$ current to $\mathrm{DC}$ voltage, $\mathrm{AC}$ voltage to $\mathrm{DC}$ voltage, temperature to $\mathrm{DC}$ voltage, a low-capacity PLC with a FBD program, which is not expensive. The FBD program is easy to design, debugging, and modify.

Using the components presented in the paper, the complex electronic protection can be used for the squirrel cage induction motor with the power up to 11 $\mathrm{kW}$. The protection can be adapted for different motors, by easily modifying numeric values such as: nominal current, currents limits, voltages, temperature and time. This protection can be easy used, also, for wound rotor induction motors, and with different type of electronic devices, at the PLC input (to measure DC currents and DC voltages), can be used for power DC motor.

\section{References}

1. S.I.Deaconu, Electrical machines (Politehnica Publishing House, Timişoara, Romania, 2016 in Romanian)

2. A. Hughes, Electric motors and drives. Fundamentals. Types and Applications (Burlington, Elsevier, MA, USA, 2006)

3. A. Iagăr, Power quality problems generated by line frequency coreless induction furnaces, Power quality harmonics analysis and real measurements data (IntechOpen, pp. 235-260, 2010)

4. S.F. Farag, R.G. Barthled, T.G. Habetler, An integrated on-line motor protection system, IEEE Industry Applications Magazine, 2 (2), pp.21-26 (1996)

5. I. Popa, G.N. Popa, Electronic devices protection, with wired and programmed structure, for threephase low voltage induction motors (Mirton Publish. House, Timişoara, Romania, pp.27-31, 2000, in Romanian)

6. X. Qi, Practical circuit design to protect motor's phase failure operation, IEEE Power Electronics and Design (APED 2010, Asia-Pacific Conference on, 6 pp., 30-31 May 2010)

7. IEC 60034-11, Rotating Electrical Machines. Thermal Protection (part 11-th, 2004)

8. Motor Book, Grundfos, Denmak, (2015)

9. L.N.Tutelea, N.Muntean, S.I.Deaconu, Dual stator winding induction generator for wind or hydro applications (Politehnica Publishing House, Timişoara, Romania, 2017)

10. G.N. Popa, C.M. Dinis, S.I. Deaconu, I.Popa, On currents asymmetry protection for three phase low voltage induction motors, International Conference on Applied and Theoretical Electricity (ICATE 2018, Craiova, Romania, pp.1-6. October 4-6 2018)

11. S.I.Deaconu, AC Electrical Machines (Politehnica Publishing House, Timişoara, Romania, 2008, in Romanian)

12. C. Pănoiu, I. Baciu, M. Pănoiu, C.D. Cunţan, Simulation results on the currents harmonics mitigation on the railway station line feed using a data acquisition system, WSEAS Transactions on Electronics, 4 (10), pp.227-236 (2007)

13. Low Voltage Motors. Motor Guide, ABB, Finland (2014)

14. TECO, Induction Motor, Totally-Enclosed FanCooled Three Phase Induction Motors, NEMA Standard EPACT (2015)

15. T. Ernst, Application of multi-function motor protection relays to variable frequency drive connected motors, Cement Industry Conference (IEEE-IAS/PCA, 26-30 April 2015)

16. Zelio PLC. SR3. User's Manual, Schneider, Germany (2010)

17. Zelio PLC. SR3 B261 BD. Product Data Sheet, Schneider, Germany (2012) 